\title{
LA CIRCULACIÓN DE MONEDA EN EL NORTE ARGENTINO DESPUÉS DE LA INDEPENDENCIA: EL CASO DE TUCUMÁN ENTRE 1820 Y 1850 *
}

\author{
ESTEBAN A. NICOLINI \\ Universidad del Norte Santo Tomás de Aquino ${ }^{a}$ \\ Universidad Nacional de Tucumán \\ MARÍA PAULA PAROLO \\ Instituto Superior de Estudios Sociales ${ }^{\mathrm{b}}$ \\ Universidad Nacional de Tucumán-CONICET
}

Currency Circulation in Northern Argentina After Independence: Tucuman Between 1820 and 1850

\begin{abstract}
The study of monetary phenomena in Argentina between 1810 and 1850 is complicated by the lack of historical sources and the coexistence of various currencies. According to previous research, the north of the country and specially Tucumán have been strongly influenced by Bolivian monetary policy and its currency devaluation throught the issue of coins Know as «feble». However, so far, a quantitative analysis of the circulation of money in this region for this period does not exist. This article shows that probate inventories have a great potential for advancing the exploration of these issues and presents an analysis of all the inventories available for Tucumán between 1820 and 1850. With this information the demand for money for this period is estimated and we confirm that

* Received 12/21/2007. Accepted 01/29/2009. Los autores agradecen los comentarios y sugerencias recibidos en la 5. ${ }^{a}$ Jornada Regional sobre Economía y Sociedad del NOA (Tucumán), así como los comentarios de los referees y los editores. Los errores son, por supuesto, responsabilidad sólo de los autores. Nicolini agradece el apoyo del Ministerio de Educación y Ciencia de España, proyecto ECO 2008-02089. Parolo agradece el auspicio de la Agencia Nacional de Promoción Científica y Tecnológica (PICT 13099) y del Consejo de Investigaciones de la Universidad Nacional de Tucumán (Proyecto 26/F302).

a Facultad de Economía y Administración en la UNSTA, 9 de julio 165 (4000), S. M. de Tucumán, Argentina. Universidad Nacional de Tucumán. Instituto de Economía en la Universidad Nacional de Tucumán, Avda. Independencia 1900 (4000), S. M. de Tucumán, Argentina. esteban.nicolini@uc3m.es.

b Cátedra de Historia Económica. Universidad Nacional de Tucumán. Avda. Independencia 1900 (4000), S. M. de Tucumán, Argentina. pparolo@herrera.unt.edu.ar.
\end{abstract}


money in circulation would have become more abundant in the 1840s, the period of highest levels of issue of «feble» coins, but without an obvious break with previous decades.

Keywords: probate inventories, Espacio Económico Peruano, «feble» coins, commercial circulation, Tucumán, Argentina, Latin America

JEL Classification: N9, N16

\section{RESUMEN}

El estudio de los fenómenos monetarios en Argentina entre 1818 y 1850 es dificultoso por la escasez de fuentes y por la coexistencia de diversos tipos de moneda. Según la literatura, el norte del país se vio fuertemente influenciado por la política monetaria boliviana de emisión de moneda feble entre 1830 y 1870 y la provincia de Tucumán habría tenido un rol especialmente importante en este proceso. Sin embargo, hasta hoy, no existen aproximaciones cuantitativas sobre la circulación de moneda para esa región en ese período. Este artículo muestra que los inventarios post-mortem tienen un gran potencial para explorar estas cuestiones y presenta los resultados del análisis de todos los inventarios disponibles en Tucumán entre 1820 y 1850 . Con esta información estimamos una demanda de dinero para este período y confirmamos que la moneda se habría hecho más abundante a partir de 1840, coincidiendo con la mayor emisión de feble, pero sin una ruptura radical con décadas anteriores.

Palabras clave: inventarios post-mortem, Espacio Económico Peruano, moneda feble, circulación mercantil, Tucumán, Argentina

\section{INTRODUCCIÓN}

En la primera mitad del siglo XIx, la circulación monetaria en el norte de lo que había sido el Virreinato del Río de la Plata estuvo marcada por la crisis y reorganización del espacio comercial generado en torno a Potosí después de las Guerras de la Independencia (1810-1825). Luego de la crisis relacionada con el enfrentamiento bélico se produjo la reintegración de un espacio monetario a partir de la emisión de moneda feble por parte del gobierno boliviano desde 1830 y hasta la segunda mitad del siglo.

Un posible punto de partida del debate relacionado con el tema de este artículo es el aporte de Carlos Sempat Assadourian (1981), quien acuña el concepto de Espacio Económico Peruano y genera dos importantes aportes metodológicos que marcarán una agenda de investigación para los años 
siguientes: por un lado destaca la importancia del mercado interno en la Hispanoamérica colonial, cuando hasta ese momento la investigación se focalizaba masivamente en la relación entre la producción minera de América y la metrópoli peninsular ${ }^{1}$. Por otro lado pone de manifiesto que el objeto relevante de investigación debería definirse en términos de un espacio regional no coincidente con las unidades políticas de los estados nación surgidos en la primera mitad del siglo XIX y que el nexo central de ese espacio geográfico estaría dado por las redes de conexiones comerciales incentivadas por la producción minera de Potosí ${ }^{2}$. Más recientemente estudios como el de Palomeque (1989) han confirmado la supervivencia de este espacio hasta el final del período colonial e incluso, reformulado, hasta bien entrado el siglo XIX, como sostienen los trabajos de Langer (1987), Langer y Conti (1991) y Nicolini (1992).

El enfoque monetario de este análisis fue desarrollado por Antonio Mitre (1981), que pone el énfasis en la supervivencia del entramado comercial ligado al Espacio Peruano después de las guerras de la independencia y el rol que la emisión de moneda feble habría tenido en ese proceso. La hipótesis presentada por Mitre y aceptada por gran parte de la historiografía le asigna a Tucumán un papel distinguido en este proceso, en tanto sostiene que la ciudad de San Miguel de Tucumán habría tenido un rol estratégico en la conformación de la red comercial-monetaria que emergió como consecuencia de la emisión de moneda feble. En particular, Mitre manifiesta que el saldo positivo del comercio exterior tucumano le habría permitido a esta provincia acumular una importante cantidad de moneda que, además, habría sido clave para hacer viable la acumulación de capital que luego, a partir de la década de 1870, habría hecho posible el surgimiento y despegue de la industria azucarera, una de las más importantes del país durante el siglo XIX.

¿Existieron en Tucumán esas cantidades apreciables de moneda boliviana? ¿Se perciben en esta provincia señales de una mayor abundancia de moneda en el período en que la acuñación de feble se hace más intensa? Recientemente, se ha reconstruido evidencia que sugiere una reconsideración de esa hipótesis. Nicolini y Scrimini (2003) han subrayado que el estancamiento de los precios observable en San Miguel de Tucumán entre 1825 y 1853 no parece consistente con un aumento significativo de la cantidad de circulante en la economía tucumana.

Este artículo intenta dar una primera visión cuantitativa que permita, de manera provisoria y limitada, aproximar una respuesta a esta pregunta, explorando más en detalle las características de la circulación monetaria en Tucumán entre 1820 y 1850 a partir de una fuente muy conocida para el estudio de otras temáticas pero escasamente explorada en las investigacio-

1 Assadourian (1981, p. 129).

2 El Espacio Económico Peruano habría abarcado desde el actual Ecuador en el Norte hasta el centro de la Argentina actual en el sur y el Paraguay en el este. 
nes sobre le situación monetaria: los inventarios post-mortem. Estos inventarios presentan información muy detallada de los bienes existentes en el momento de la muerte del propietario de los bienes inventariados y en un porcentaje importante de casos menciona la cantidad de dinero en efectivo.

Hasta ahora el estudio de los fenómenos monetarios para el período anterior al establecimiento de una autoridad monetaria centralizada se basaba en el análisis de las reglamentaciones emanadas desde el sector público y los debates de las autoridades políticas, como se observa en los estudios de Segretti (1975); o en los estudios de caso de personajes económicamente relevantes - grandes comerciantes, hacendados, etc. - a través de sus libros contables, como los realizados por Schmit (2003). En el primer caso se corre el riesgo de concentrarse demasiado en la mirada que las autoridades hacen de la problemática, enfatizando aquello que es considerado un "problema» digno de ser afectado por algún tipo de intervención de la autoridad; la circulación moneda falsa puede, por ejemplo, recibir una desproporcionada atención. En el segundo caso, resulta difícil extender el análisis fuera de una clase o grupo social muy específico, para el cual la utilización de los libros contables era una práctica cotidiana. Recientemente Roy Hora (2006) enfatizó el rol de los inventarios post-mortem como una fuente valiosa para el análisis de los activos reales y financieros de ciertos grupos económicos en Buenos Aires para un período bastante similar al estudiado en este artículo ${ }^{3}$.

Nuestro trabajo se basa precisamente en este tipo de fuente. Su aporte consiste en una mirada a la circulación monetaria desde el punto de vista de los usuarios de la moneda y haciendo una aproximación que, aunque limitada como toda aproximación, permite tener una visión un poco más completa del uso de la moneda en estratos transversales de la sociedad y aportar análisis cuantitativos imposibles con otro tipo de fuentes. En este sentido, además de explorar el tipo de moneda utilizada y el porcentaje de riqueza mantenido en efectivo durante el período, nuestra fuente permite la estimación de una demanda de dinero que nos ayuda a entender con más detalle las motivaciones por las cuales el público mantenía una cierta cantidad de moneda en su poder y en qué sentido la mayor riqueza estimularía una mayor cantidad de efectivo acumulado.

El resto del trabajo se organiza como sigue: en la sección 2 se presenta el contexto histórico en el que se enmarca el estudio introduciendo algunos aspectos del debate sobre las conexiones mercantiles en el Norte argentino y la emisión de moneda feble boliviana. En el apartado 3 se describe y analiza la fuente utilizada, destacando sus limitaciones y sus potencialidades para estudiar la historia monetaria. La cuarta sección se ocupa de precisar

3 Otros trabajos usando inventarios para la zona del Río de la Plata en los siglos XVIII y XIX, mencionados también por Hora, son Mayo (1991), Amaral (1998), Garavaglia (1999) y Johnson (1999). 
y describir los tipos de moneda que circulaba en la región en función de los estudios precedentes sobre el tema. En la sección 5 se examinan los datos extraídos de las fuentes. En el apartado 6 se adelantan algunas conclusiones. Los resultados más significativos del análisis econométrico se presentan en el apéndice.

\section{TUCUMÁN EN LA PRIMERA MITAD DEL SIGLO XIX}

Cuando hablamos de Tucumán en la primera mitad del siglo XIX, nos estamos refiriendo, en líneas generales, a un período demarcado por el fin del gobierno colonial, las guerras de la independencia y la crisis provocada por la ruptura del eje comercial Potosí-Buenos Aires, por un lado, y la organización del Estado y mercado nacionales que enmarcaron el desarrollo de la industria azucarera (actividad que permitió a la provincia insertarse en el modelo agro-exportador), por el otro. En esos más de cincuenta años de historia tucumana, se alteraron todos los aspectos de la vida de sus actores. La crisis de legitimidad, el asentamiento del ejército, la crisis de la actividad mercantil, el paso al status de provincia, la abolición de la esclavitud, entre otros factores, nos hablan de cambios en la delimitación del espacio, las prácticas políticas, las relaciones sociales y el perfil económico de la provincia.

Durante todo este período de grandes trasformaciones, Tucumán se caracterizó por la notable densidad de su población, fenómeno que se observa desde épocas muy tempranas ${ }^{4}$. El importante potencial demográfico que provenía de la época precolombina y colonial fue incrementándose paulatinamente hasta alcanzar las tasas más elevadas a mediados del siglo XIX.

Se calcula que la población que habitaba en la jurisdicción de San Miguel de Tucumán a fines del siglo XVIII rondaba los 20.104 habitantes, de los cuales 4.087 (el 20 por cien) residían en la ciudad ${ }^{5}$. Para los años posteriores sólo disponemos de estimaciones como las del General Ángel Malaspina, quien en 1789 calculó una población de 22.809 habitantes, o la del Obispo Angel Mariano Moscoso, que en 1801 estimó 23.700 ${ }^{6}$. En 1845 el Gobernador Celedonio Gutiérrez mandó levantar el censo de la población y de los productos naturales del territorio, cuyos resultados consignan 57.876 habitantes, de los cuales 16.822 (casi el 30 por cien) residían en la capital de la provincia ${ }^{7}$. Asimismo, el Censo levantado

4 En 1801 era el territorio más densamente poblado, siendo su densidad diez veces superior a la media del resto del Virreinato del Río de la Plata (Pucci, 1992, p. 10).

5 Datos extraídos de Larrouy (1927), citado por Jorge Comadrán Ruiz (1969, pp. 80-81).

${ }^{6}$ Citado por López de Albornoz (2000, pp. 63-64) y Bascary (1999, p. 35).

7 Archivo Histórico de Tucumán (en adelante AHT), Sección Administrativa (en adelante SA), vol. 63 , t. 2, año 1845 . 
durante la Confederación Argentina (1858) arrojó la cifra de 83.545 habitantes ${ }^{8}$.

A partir de estos datos, las estimaciones de las tasas de crecimiento anual intercensal muestran la tendencia de un ritmo fluctuante aunque sostenido desde fines del período colonial, cuyo promedio se ubicaría en el orden del 20 por mil. Esto ubicaba a Tucumán en una situación diferente respecto del resto de las ciudades de la Intendencia, caracterizadas, en general, como expulsoras de población. Desde la segunda mitad del siglo XVIII hubo, entonces, un lento pero constante crecimiento demográfico ${ }^{9}$.

Del mismo modo que la evolución demográfica, el desarrollo de la economía provincial puede explicarse en un contexto regional. En la primera década del siglo XIX el imperio hispánico de América inició su rápida desintegración, que derivó en la ruptura, cambio y reacomodamiento del espacio económico peruano. El esquema de integración espacial, basado en la especialización productiva regional y en los intercambios comerciales, sufrió profundas transformaciones a partir de 1810, ocasionadas, entre otras cosas, por las guerras de la independencia y por los nuevos límites nacionales que surgieron durante las mismas o inmediatamente después.

Con la crisis producida por la independencia, disminuyó el tráfico ascendente de mercadería y la consiguiente provisión de mulas para el transporte de montaña - aunque se mantuvieron lazos comerciales con algunas ciudades altoperuanas-. Al mismo tiempo se redujo notablemente el flujo descendente de plata boliviana, con lo cual prácticamente desapareció la principal fuente de metálico de la economía provincial que intentó cubrirse con la emisión local de moneda («Moneda Federal») o con moneda «falsa» acuñada en provincias vecinas («Moneda Güemes»). A partir de entonces, si bien se fortaleció la dependencia comercial con respecto al puerto de Buenos Aires - que pasó a ser el principal comprador de los excedentes productivos provinciales-, Tucumán siguió inserta en el antiguo espacio económico peruano, de manera que a lo largo de toda la primera mitad del siglo XIX sus intercambios mercantiles se desenvolvieron bajo el influjo de diversas fuentes de aprovisionamiento de bienes importados y no dependió de un solo mercado de consumo para la colocación de sus productos.

Posteriormente a la crisis producida por la independencia, la repercusión de diversas coyunturas políticas y militares sobre el comercio tucu-

\footnotetext{
8 AHT, SA, vol. 84, año 1858.

9 Los estudios de López de Albornoz y Pucci, sobre la población de Tucumán a fines de la colonia y en el transcurso del siglo XIX, respectivamente, permiten afirmar que desde fines del siglo XVIII la población de la jurisdicción de San Miguel de Tucumán mantuvo un ritmo de crecimiento sostenido y alcanzó su máximo nivel — del 28,6 por mil- en el período 1845-1858, el que no será superado en ningún otro momento de la historia provincial (López de Albornoz, 2000; Pucci, 1992).
} 
mano (como los bloqueos al puerto de Buenos Aires y algunos episodios de las guerras civiles), moderarán la inclinación de la provincia hacia el Atlántico —-tendencia que se venía manifestando desde fines del siglo XVIII-, reorientándola parcial y transitoriamente hacia el Pacífico y el mundo andino conectado a sus puertos ${ }^{10}$. Comenzaron, entonces, a cobrar mayor importancia relativa las actividades relacionadas con la nueva red de intercambios: la construcción de carretas; el curtido y elaboración del cuero; la producción tabacalera y la de azúcares y aguardientes, mientras subsistieron las artesanías textiles y productos agropecuarios para consumo interno.

La prolongada presencia del Ejército Auxiliar del Norte en la región y los años de guerras civiles dejaron a la economía de la provincia en un estado financiero desesperante; a un importante segmento de las clases mercantiles diezmadas y el stock ganadero prácticamente agotado. A pesar de todos los inconvenientes que debió enfrentar en las primeras décadas del siglo XIX, el comercio siguió desempeñando el rol más destacado entre las actividades económicas de Tucumán. Con la llegada de Alejandro Heredia al poder en el año 1832 y el reordenamiento político operado por entonces bajo los lineamientos impuestos por el rosismo, las transacciones mercantiles recuperaron su ritmo. El circuito de comercialización de mayor intensidad y dinamismo siguió siendo el que se vinculaba con la ciudad puerto, desde y hacia donde los envíos eran regulares todo el año; Córdoba se mantuvo como uno de los principales mercados receptores del tabaco tucumano y los contactos con la región cuyana y las provincias del norte, abrieron paso a la entrada de los productos de la provincia en los mercados trasandinos y boliviano, respectivamente ${ }^{11}$.

La reactivación de la acuñación de moneda fuerte (con ley de diez dineros) y feble (con ley de ocho dineros) boliviana entre 1830 y 1870 habría repercutido favorablemente en este proceso de redinamización de la actividad mercantil ${ }^{12}$. En ese marco, "la moneda fuerte [...] siguió el camino de la costa en calidad de retorno a las importaciones de ultramar; la feble, en cambio, se concentró en los mercados regionales, sobre todo, en el norte argentino y sur peruano» ${ }^{13}$.

Estudios recientes enfatizan la posibilidad de que el metálico fluyera parcialmente hacia el puerto no sólo para pagar las importaciones, sino

10 Nicolini (1992); Campi (1996).

11 Tucumán enviaba especialmente suelas y cueros, y —en segundo término- productos de la industria artesanal y doméstica como arroz, pellones, riendas, aperos, carretas, bateas y quesos. Recibía de Buenos Aires exclusivamente artículos de ultramar (tocador, ferretería, lencería, loza, cristalería, etc.).

${ }^{12}$ El porcentaje de moneda feble dentro del total comenzó siendo sólo un 14 por cien en el quinquenio 1830-1834 y creció sostenidamente hasta alcanzar un 40 por cien en 1840-1844 y un 82 por cien en 1850-1854 (Mitre 1986, cuadro 6, p. 34).

13 Mitre (1986, p. 33). 
también como resultado de una moneda fiduciaria devaluada que generaba fuertes variaciones del tipo de cambio y de los precios relativos. En este sentido, Nicolini (1992) sostiene que la moneda tendía a fluir desde el interior del espacio para pagar las importaciones de ultramar, pero según Irigoin (2003), una porción de esa moneda podría haberse mantenido en las provincias del Norte y quizás no ser tan visibles porque se la mantenía como reserva de valor a través del atesoramiento.

La política monetaria del estado boliviano - uno de cuyos elementos es la acuñación de una moneda que tiene menor valor para la exportación a ultramar-, habría estimulado, entonces, la actividad económica interna, facilitando los intercambios y favoreciendo la mercantilización de la producción local y regional ${ }^{14}$.

La utilización de la moneda en esta región parece haber permeado a varios sectores sociales y actividades económicas y haber sido bastante común en varios tipos diferentes de transacciones. En muchos casos el uso de moneda coexistía con el trueque y el pago diferido basado en un mercado informal de crédito al consumo (consumo a fiado), pero la utilización de metálico no era excepcional y se la tomaba como algo cotidiano en muchas instancias del día a día ${ }^{15}$.

Las fuentes judiciales son especialmente útiles para ilustrar este punto, ya que son ricas en información sobre las formas cotidianas de intercambio en tanto recogen testimonios y confesiones de acusados, demandantes y testigos que reconstruyen con sus dichos los hechos de los que fueron partícipes. En el juicio contra Juan Domingo Chávez, quien en 1847 fue detenido por robo, se combinan las menciones de la práctica del trueque con el uso de moneda; el acusado confesaba en su declaratoria ser peón jornalero y haber comprado una yegua a otro peón (Juan Medina) "por un corte de gerga y doce reales plata» ${ }^{16}$.

La moneda en efectivo aparece también, por ejemplo, en las apuestas de juego, actividad bastante difundida entre las clases populares en esta época ${ }^{17}$. En un sumario seguido a un sargento por haber estado jugando a los naipes con unos soldados, uno de los testigos declaraba que

«[... ] habiendo pasado al lugar a practicar una diligencia vio una reunion, que la buelta se arrimó a ella al mismo tiempo que llegó el

14 La situación monetaria argentina en 1862 —al final del período de nuestro análisis- presenta una pluralidad de monedas con el peso plata principalmente boliviano circulando en el interior — que había sido la moneda corriente de la Confederación (1853-1862) — y el peso papel de la provincia de Buenos Aires con curso forzoso en esa provincia (Roberto Cortés Conde, 1989).

${ }_{15}$ Sabemos que la existencia de trueque y sobre todo la de la transacción basada en la deuda fue bastante común en muchas economías de baja sofisticación financiera (Holderness, 1976; Muldrew, 1998; Nicolini y Ramos, 2006).

16 AHT. Sección Judicial del Crimen (en adelante SJ del Crimen), caja 19, exp. 40, año 1847.

17 Cfr. Mayo (1998); Parolo (2006). 
Capitan y sorprendió a los soldados quitandoles el poco dinero que jugaban, que habiendo exsigido del declarante el dinero que jugaba le contestó qe él no había jugado, y se retiró» ${ }^{18}$.

Las pulperías eran otro de los ámbitos en los que el dinero discurría con frecuencia, no sólo por las compras diarias de mercadería para abasto de la población - cuyo pago en moneda quedó asentado en libros de Caja de este tipo de negocios-, sino también porque funcionaban como casa de juegos y de empeños ${ }^{19}$. Testimonios al respecto abundan entre los expedientes judiciales como el seguido en 1812 a Juan Antonio, esclavo del Convento de San Francisco, quien

« [...] estando jugando con otros, en la pulpería de D. Ignacio Villafañe, se hallaba allí un tal Venavidez, y haviendole arrebatado al declarante la Plata se salio fuera, y el tras el, á cobrarle, y pr qe le bolbio sólo quatro reales le cometio el otro con una puñalada de que conserva una muy pequeña sicatris $[\ldots ..]{ }^{20}$.

También aparece de manera recurrente la existencia de dinero guardado entre las pertenencias de individuos de cortos recursos. Entre los bienes inventariados de un mulato se hallaron una alforjita y en ella «una chuspita de Abestruz con onze rrs de plata sellada [y] otra [...] con veinte pesos un rrl moneda corrte» ${ }^{21}$. Otro caso ilustrativo es el de Eustaquia Toscano, quién presentó demanda contra un cliente ocasional que confesó

«[...] como a las dos o tres de la tarde se fue a casa de la Toscano con dos compañeros a tomar aloja, y pa cambiar un real se entro ella adentro. La siguio, entró al cuarto y levantó tres pesos que había sobre la cama, ella le reclamó y él se los devolvió diciéndole que lo he tomado de broma» ${ }^{22}$.

Por otra parte, el cobro de jornales, salarios o adelantos de dinero por trabajos "personales», fueron también causales de numerosas demandas que dan cuenta del uso de efectivo en el pago por servicios. Juan José Miranda, conchabado en una tropa de carretas, se escapó a pesar de que había recibido por adelantado un salario de doce pesos, dinero con el que compró diecisiete caballos y una yegua ${ }^{23}$. Del mismo modo, un tal José

18 AHT, Sección Administrativa, vol. 59, año 1843.

19 Cfr. Parolo (2008).

20 AHT, SJ del Crimen, caja 16, exp. 17, año 1812.

21 AHT, SJ del crimen, caja 12, exp. 35, año 1800.

22 AHT, SJ del Crimen, caja 17, exp. 27, año 1819.

23 AHT, SJ del Crimen, caja 13, exp. 2, año 1800. 
Blanco, peón de tropa, recibió la cantidad de dieciséis pesos a cuenta de un viaje para Bolivia pero se ocultó en el monte, donde permaneció hasta tres días después de haberse marchado la tropa ${ }^{24}$.

Pero el ejemplo más elocuente del uso y circulación de metálico entre los sectores populares lo ofrecen las manumisiones (compra de libertad) que muchos esclavos consiguieron para sí o para sus hijos. La esclava Ana Torres, por ejemplo, reclamó ante las autoridades porque su finado esposo había pagado a su amo 200 pesos a cuenta de su libertad, pero seguía bajo servidumbre hasta tanto se pagaran los otros 200 pesos que faltaban para completar la venta. Sin atender a este compromiso, el amo la vendió a otro individuo por «solos docientos ps». Ante esta circunstancia, la demandante acudió a la justicia solicitando ser declarada libre y «no estar obligada á reintegrarle á este los docientos ps en qe me compro, por la mala fe con qe procedió á hacer la compra». Si, en caso contrario, no se le otorgaba la libertad, pidió se le conceda "pagarlos con mi industria y trabajo, contribuyéndole una cuota mensual» ${ }^{25}$. Otro caso fue el de una esclava liberta que en 1817 reclamaba ante el Alcalde de $1^{\circ}$ voto que hacía más de once años que era libre y que con su trabajo personal «tan mecanico y esteril qual puede ser el de una muger», había logrado juntar «algunos pesos» para comprar la libertad de su hija ${ }^{26}$.

En suma, la documentación disponible permite inferir que el dinero efectivo no sólo circulaba entre los sectores mercantiles, sino que también lo hacía con bastante fluidez entre los sectores populares tanto en las compras al menudeo, como en las apuestas de juego, el cobro de salarios, el pago de deudas o empeño de prendas. Sin descontar que en algunos casos se guardaba o ahorraba para algún fin determinado, como en el caso de las manumisiones de esclavos.

\section{LOS INVENTARIOS POST-MORTEM COMO FUENTE PARA LA HISTORIA DE LA MONEDA}

La base de datos usada en este artículo se construyó a partir del análisis exhaustivo de todos los inventarios disponibles en la Sección Judicial del AHT entre los años 1820 y 1850 . Fueron reconocidos a partir de las menciones en Materia de temas como «Su testamentería», "Partición de Bienes y Herencia», etc. Esto incluye 162 inventarios.

El expediente tipo consta de una primera parte en la que se informa al juzgado de la muerte de una persona y se solicita copia del testamento. Luego de la copia del testamento se nombran albaceas y peritos y se proce-

\footnotetext{
24 AHT, SA, vol. 67, año 1848 .

25 AHT, Sección Judicial Civil (en adelante SJC), caja 58, exp. 24, año 1820.

26 AHT, SA, vol. 26, año 1817.
} 
de al inventario. A veces el inventario se realiza primero sin valuación de los bienes y luego se procede a asignar precio a cada uno de los bienes en un momento diferente y con la presencia de peritos tasadores. Al final, si no hay reclamos o disputas por inventarios incompletos o indebidamente realizados, se divide la herencia entre los herederos haciendo una hijuela con los detalles que le tocan a cada uno de los mismos.

De todos los expedientes analizados se han descartado aquellos que son ilegibles, no incluyen tasación de los bienes, incluyen información que generen dudas razonables sobre la confiabilidad de los datos (por ejemplo el paso de muchos años entre la muerte del propietario de los bienes y la realización del inventario o quejas por parte de involucrados de manifiestas irregularidades, etc.). Esto ha reducido nuestro conjunto de datos a 133 inventarios.

La distribución temporal de los datos tiene el siguiente perfil.

GRÁFICO 1

CANTIDAD DE INVENTARIOS ANALIZADOS, 1820-1850

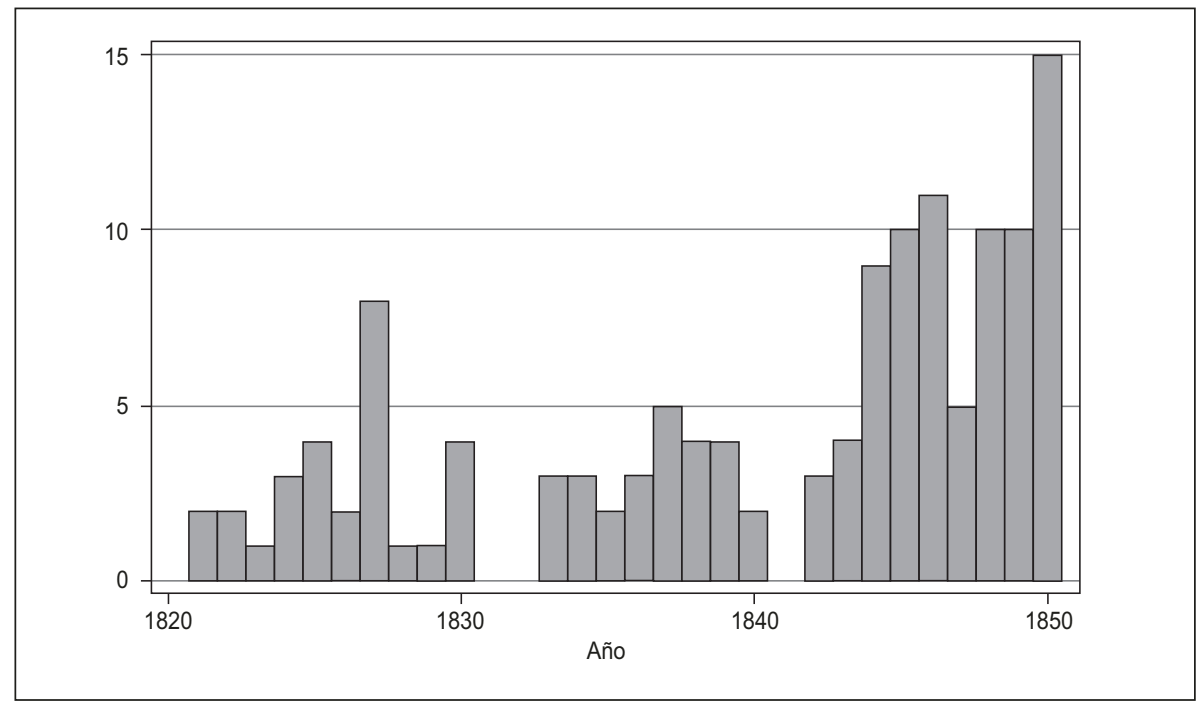

Fuente: Ver texto.

De los 133 inventarios hay 47 que mencionan la existencia de dinero en efectivo. La distribución temporal de estos 47 inventarios es la siguiente. 
GRÁFICO 2

CANTIDAD DE INVENTARIOS INCLUYENDO EFECTIVO, 1820-1850

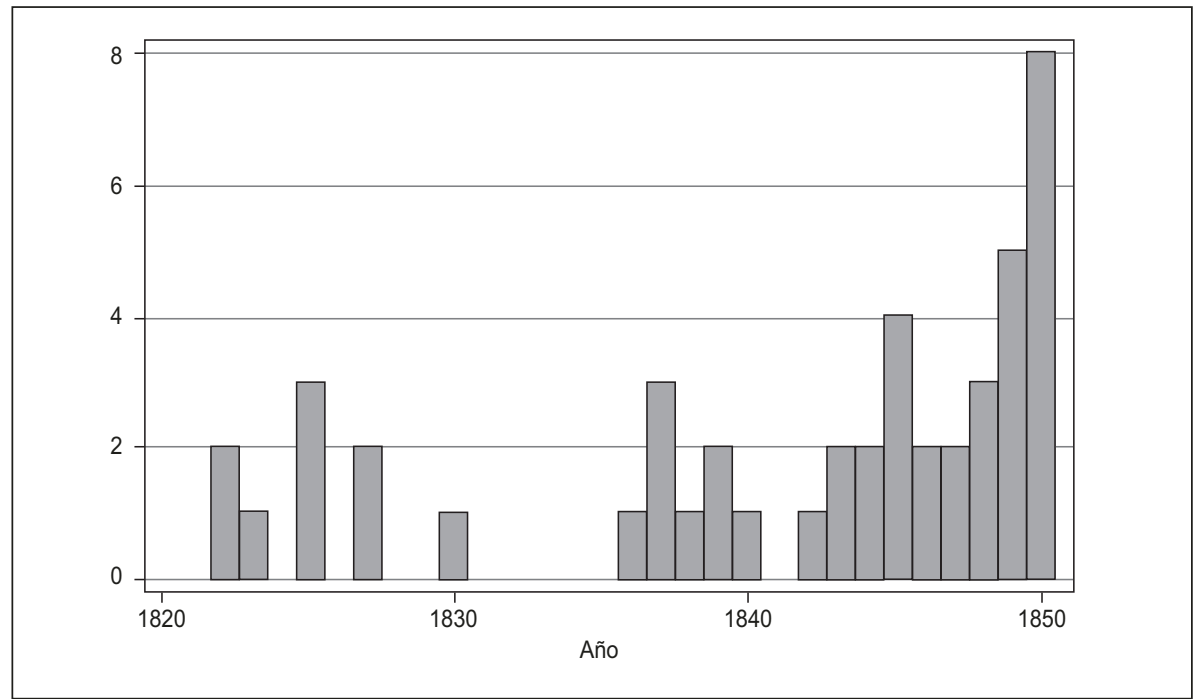

Fuente: Ver texto.

Aunque se mantiene un perfil similar al del total de inventarios, se hace más intensa la concentración de inventarios en los últimos años de la muestra. Entre 1821 y 1830 hay un 32,14 por cien de inventarios mencionando efectivo, mientras que en la década de 1841 a 1850 el porcentaje sube a 37,66 por cien. Esto puede sugerir una intensificación de la monetización a partir de 1840 en línea con lo afirmado por Mitre (1981).

Los inventarios post-mortem se han usado como fuente histórica para estudiar una variedad amplia de temas: la productividad agrícola en el caso de Overton (1979) y Allen (1988); los patrones de consumo en De Vries (1996), Ramos Palencia (2001) y Mayo (1991); Holdeness (1976) los utilizó para analizar las características de los mercados de crédito informales; Mayo (1991) y Hora (2006) para examinar las estrategias de inversión, entre otros. Recientemente Nicolini y Ramos Palencia (2006) han sugerido que esta fuente también puede usarse para analizar los patrones de utilización de la moneda.

En general se reconoce que los inventarios post-mortem tienen una serie de inconvenientes a la hora de ser utilizados como fuente histórica. Los dos más importantes en nuestro caso son que en general los inventarios no representan igualmente a todas las clases sociales, sino que suelen estar sesgados hacia los grupos más acomodados y que además puede existir un incentivo para la ocultación de dinero después de la muerte de la persona sobre cuyos bienes se realiza después el inventario, lo cual sesgaría la infor- 
mación obtenida a través de los mismos. El primer problema es difícil de resolver con la información que se dispone para Tucumán en la primera mitad de siglo, pero para el caso español se ha demostrado que los resultados no varían dramáticamente cuando este problema puede resolverse ${ }^{27}$. El segundo problema de nuestra fuente aparece en casi todos los documentos de naturaleza administrativa o judicial: lo único que es posible medir es lo declarado ante la justicia y lo ilegal pasa inmediatamente a generar un problema de sesgo ${ }^{28}$. En nuestro caso este problema puede verse reducido en cierta forma, dado que los inventarios se realizan con la participación de varias partes teóricamente neutrales y no involucradas (albaceas y tasadores) y al mismo tiempo por la existencia de intereses contrapuestos de los diferentes herederos para que la totalidad de los bienes sea incluida en el inventario con su justo precio. De hecho, en varios casos se observa que alguno de los herederos reclama la confección de un nuevo inventario por posible ocultación de bienes. La ocultación o desaparición de bienes debería ser arreglada y coordinada por todos los herederos o permanecer completamente sin notarse para los que no participaron del arreglo; de otra forma sería difícil aceptar que algunos de ellos admitirían esa reducción del cuerpo total de bienes que se traduce, obviamente, en una disminución de lo que perciben de la herencia. Podrían hacerse varias consideraciones acerca de los lazos familiares y de proximidad entre herederos y el probable comportamiento en un caso como éste; nos basta, para nuestro caso, sugerir que no parece que esta fuente deba estar más dañada por el comportamiento ilegal que otras fuentes ampliamente usadas para analizar la vida económica del pasado.

\section{LAS MONEDAS CIRCULANTES EN TUCUMÁN}

En todos los inventarios analizados la unidad de cuenta es el peso. Cuando se menciona el dinero en efectivo se utilizan varias expresiones típicas y, por lo menos aparentemente, sinónimas: "plata sellada», "pesos fuertes», «moneda corriente», «tantos pesos plata en moneda corriente» ${ }^{29}$.

También parece claro que la mención de pesos plata hace referencia a una unidad de cuenta no sólo cuando se menciona efectivo. Por ejemplo en

27 Nicolini y Ramos Palencia (2006) usan datos de un censo general de población para reponderar la muestra y evitar el sesgo mencionado. En nuestro caso esto es imposible de realizar con la información disponible.

${ }^{28}$ El caso típico es el de evaluación de la actividad económica a través de fuentes impositivas: toda la actividad económica ilegal o no declarada genera un sesgo en la estimación histórica. Ver por ejemplo Newland (2000) sobre estimaciones de producto usando el diezmo, o Palomeque (1989) para estimaciones de la actividad comercial usando las fuentes aduaneras.

${ }^{29}$ En varios expedientes esta equivalencia entre las denominaciones se hace explícita, como por ejemplo «En plata sellada moneda corriente». AHT, SJ, exp. 87, fojas 23 (a partir de ahora citaremos las fuentes con las iniciales AHT, SJ, 87-23). 
un inventario de 1849 se menciona la existencia de «25 pesos plata puestos a réditos con el 3 por cien ${ }^{30}$. O sea que no es una descripción de la existencia física de esa plata sino de una deuda consignada en esa moneda.

Según investigaciones anteriores, en Tucumán habrían existido diversos tipos de moneda acuñadas por diferentes instituciones e individuos y de variada calidad ${ }^{31}$. En principio durante los primeros años posteriores a la independencia, circuló todavía la moneda acuñada durante el período colonial. No tenemos datos precisos de hasta cuándo circuló esta moneda, aunque rápidamente luego de la ruptura del sistema colonial ya se habla de escasez de moneda ${ }^{32}$. La otra moneda fundamental es la que comienza a acuñar el estado boliviano cuando su sector minero comienza a recuperarse después del estancamiento sufrido como consecuencia de la guerra de independencia. La moneda acuñada en este período fue similar en peso y ley a las antiguas piezas coloniales hasta 1830, pero según Irigoin (2006) la masiva exportación de las mismas para pagar las importaciones generó escasez de moneda y provocó el comienzo del debasement. En 1830 se comienza acuñar la moneda «feble», que, con menor contenido de plata que la «fuerte», se fue convirtiendo paulatinamente en la pieza central de la política monetaria boliviana: en la primera mitad de la década de 1850 el 82 por cien de la emisión global de moneda era de pesos feble ${ }^{33}$.

Además de estas monedas de relativamente alta calidad, valor comprobable y mayoritaria aceptación existieron otras ${ }^{34}$. La más relevante es la llamada moneda federal, una moneda macuquina, acuñada desde mediados de 1820 por una primitiva casa de moneda instaurada en Tucumán a cargo del que fuera talla mayor de la Casa de Moneda en Potosí, Pedro Benavídez. Los escasos medios técnicos disponibles en la provincia hicieron que esta moneda nunca lograra un cuño refinado y por tanto fuera relativamente fácil de falsificar. Sólo unos meses después de ponerse en circulación la moneda federal, comenzaron a circular monedas falsas de calidad variable, algunas muy similares en contenido de plata a la moneda oficial tucumana y otras fabricadas casi exclusivamente de cobre y apenas bañadas con una delgada pátina de plata para semejar las auténticas ${ }^{35}$. El Banco de Rescate y Amonedación, encargado de la acuñación de la moneda federal auténtica,

30 AHT, SJ, 87-24.

31 Las referencias más importantes sobre el circulante en Tucumán en este período son Segretti (1975), Ávila (2003), Catena (1988), Lizondo Borda (1948).

32 Las menciones de «escasez de moneda» no deben tomarse literalmente como que no existe ninguna moneda en circulación. La Ley de Gresham nos sugiere que ante la existencia de monedas de diversa calidad, la buena será escasa no porque no exista esa moneda sino porque no se la observa en circulación.

33 Mitre (1986).

34 Aunque la feble era obviamente de calidad inferior a la fuerte.

35 A estas monedas falsas también se las llamó «monedas Corro» por ser Nicolás Corro y su hijo Pablo dos falsificadores que se hicieron conocidos al ser capturados y enjuiciados en 1821 (Catena, 1988, p. 29). 
existirá hasta agosto de 1821, pero la moneda acuñada por éste y la falsificada durarán más tiempo. La depreciación de la moneda federal, tanto la oficial como la falsa, fue rápida y en enero de 1824 el gobierno acepta esta moneda sólo a un tercio de su valor ${ }^{36}$. Esta moneda, pero sobre todo sus imitaciones, generaron diversos problemas al público, a los productores y comerciantes y al erario público. Luego de intensos debates políticos e incluso algún tumulto político, el 25 de febrero de 1824 la moneda es declarada extinta y paulatinamente desaparece de circulación ${ }^{37}$.

También habría circulado en Tucumán, aunque quizás de manera no tan masiva, la moneda llamada Güemes, que, originada principalmente en la ciudad de Salta, era moneda acuñada por particulares con la tácita autorización del gobierno de Güemes en Salta desde finales de 1817 y que luego fuera resellada por ese gobierno intentando darle cauce legal y obligatorio ${ }^{38}$.

También existió una efímera experiencia de papel moneda en Tucumán cuando en febrero de 1841 el "Congreso de los Agentes de los Gobiernos de la Liga del Norte contra el tirano Rosas» creo el Banco Hipotecario. Si bien la ley de creación de este banco justifica su creación por la necesidad de escasez de moneda circulante y la consecuente paralización de las transacciones, el verdadero objetivo habría sido según Bousquet (1878, p. 47), «fabricar moneda destinada a proporcionar recursos al gobierno por la emisión de billetes de curso forzoso no convertibles a la vista» para sostener al «Ejército Libertador» al mando del General Lavalle.

Este papel moneda fue tan resistido que apenas un mes después de la creación del banco el gobierno de la Liga del Norte tuvo que emitir un decreto insistiendo en la obligatoriedad de recibir su moneda. Cuando la Liga es derrotada en el frente militar unos meses después, los billetes perdieron su convertibilidad y dejaron rápidamente de circular.

Curiosamente, como se mencionó al comienzo de esta sección, las referencias a la moneda en los testamentos se hacen casi exclusivamente en términos de «pesos plata». La moneda federal aparece sólo puntualmente en algunos inventarios que analizaremos en la sección cinco.

Más allá de la presencia, no muy visible en los inventarios, de monedas locales y/o falsificadas, las dos monedas que tenían mayor aceptación era la moneda remanente de la época colonial y la moneda acuñada por el estado

36 Poco antes de la resolución de la extinción de la moneda federal, la legislatura administró una política errática al intentar asignarle un valor oficial a la obviamente depreciada moneda federal. Por ejemplo, una ley del 9 de febrero de 1824 asigna a la moneda federal de dos reales el valor de un real, mientras que una resolución de la misma legislatura de dos días después asigna a la moneda federal «que no manifiesta ser adulterada» su valor facial y a la moneda "que no es de plata sino adulterada» le reconoce un valor oficial de $1 / 8$ del valor facial.

37 Los detalles sobre este breve episodio de política monetaria provincial pueden consultarse en Catena (1988).

38 Es imposible estimar con precisión la acuñación de esta moneda irregular, pero se estiman que se acuñaron unos 26.000 pesos, de los cuales la mitad fueron resellados por el gobierno de Salta dándoles cierta legitimidad oficial (Segretti, 1975, pp. 53-58). 
boliviano en el período independiente. Las referencias indirectas sugieren un reemplazo, no sabemos si rápido o paulatino, de la primera por la segunda. Sin embargo, en los inventarios no se hace una diferenciación a la hora de consignar la moneda. Se habla de pesos plata pero sin distinguir si se trata de los coloniales o de los bolivianos (que en su versión feble, que es la que se sospecha circulaba en esta región, tenían menor contenido metálico). Los pesos plata mencionados antes de 1825 tienen que ser necesariamente los remanentes de las acuñaciones de la época colonial, pero los mencionados al final de nuestro período en estudio deben ser casi con seguridad los acuñados por el nuevo estado boliviano y, seguramente, muchos de ellos del tipo feble. En el único inventario en el que se menciona la plata boliviana explícitamente con ese nombre es el de Manuel María Méndez de 1850 , pero ésta es la excepción ${ }^{39}$. Parece improbable que todo el efectivo mencionado en los otros inventarios fuera de plata remanente de la época colonial o de pesos fuertes bolivianos, con lo cual la conjetura más probable es que existió un paulatino reemplazo de la plata de la época colonial por moneda feble, sin que esto se haga visible en los inventarios, lo que sugeriría una aceptación más o menos generalizada de la moneda feble boliviana como para no distinguirla en esta fuente de la otra moneda.

Si esta hipótesis fuera cierta, dado que el valor intrínseco de la moneda feble boliviana era menor que el de moneda de la época colonial, se esperaría una declinación del valor de la moneda en relación a la plata labrada o en lingotes. Si la relación plata/oro se hubiera mantenido constante, también esperaríamos un aumento del valor del oro en relación a la moneda. Exploraremos esta posibilidad en la sección cinco.

En este contexto de coexistencia de diversas monedas es importante reconocer la posible existencia de los efectos de la ley de Gresham, cuyo principio es que si existen dos monedas en circulación con diferentes valores intrínsecos pero el mismo valor facial y existe algún tipo de penalización para los que no aceptan ambas por su valor facial, los poseedores de moneda ofrecen predominantemente la moneda mala y los vendedores de bienes o servicios deben aceptarla. En este contexto la moneda mala desplaza a la buena de la circulación. En nuestro caso existieron intentos de las autoridades provinciales de que la moneda federal sea aceptada a su valor facial o a tipos de cambio oficiales, lo que podría haber disparado por momentos y en relación a esa moneda lo establecido en la ley de Gresham.

En la práctica puede darse que se use la moneda buena (oro sellado y monedas bolivianas de plata fuerte y feble boliviana) más intensivamente para el atesoramiento y las monedas malas (federal, Güemes, falsificada) para la circulación ${ }^{40}$. En nuestro caso lo más probable es que las peores monedas se

\footnotetext{
39 AHT, SJ, 89-8.

40 Los diferentes tipos de papeles que pueden considerarse moneda emitidos en Buenos Aires podrían caracterizarse como un caso especial, dado que no tenía las características que le per-
} 
usaran para la circulación en las transacciones cotidianas y de orden local, mientras las monedas «buenas» se usaran, además de como herramienta de atesoramiento, para el pago de las importaciones provinciales en los intercambios del comercio interregional e internacional ${ }^{41}$. Esta separación de los diferentes usos de la moneda podría devenir en una segmentación de la demanda de dinero, tema que trataremos nuevamente en la próxima sección.

\section{RESULTADOS DE LOS ANÁLISIS DE LOS INVENTARIOS}

El primer análisis posible con la información de estos inventarios es la estimación de una demanda de dinero. La demanda de dinero es una formalización de los determinantes de la tenencia de efectivo por parte de los agentes económicos. En general la teoría sugiere que la gente demanda dinero en función de su ingreso o riqueza, la tasa de interés, algunas variables relacionadas con la eficiencia del sistema financiero, etc. ${ }^{42}$.

En un contexto histórico, en la mayoría de los análisis de los cambios de precios en el largo plazo se ha utilizado la ecuación de Fisher, como en los estudios de Lindert (1985), Goldstone (1984) y Nicolini y Scrimini (2002), que ceteris paribus supone que la demanda de efectivo crece proporcionalmente al ingreso de los individuos ${ }^{43}$. Nuestra estimación de un modelo explícito de la demanda de dinero nos permite explorar este supuesto con más detenimiento.

Usando la metodología propuesta en Nicolini y Ramos (2006), la forma asumida de la demanda de dinero es la siguiente

$$
M_{i}=\alpha+\beta Y_{i}+u_{i}
$$

donde $M_{i}$ es la cantidad de dinero en efectivo que el individuo $i$ tiene entre sus pertenencias personales (y que aparece consignado en el inventario), $Y_{i}$ es la riqueza del individuo $i$ (también consignada en el inventario), $\alpha$ y $\beta$ son los parámetros a estimar y $u_{i}$ son errores normal e idénticamente distribuidos. En este caso, y en este nivel de desarrollo de la investigación, no es posible agregar otras variables de interés tradicionalmente incluidas en este

mitan ser considerado una moneda buena (por la volatilidad de su cotización) pero al mismo tiempo no era aceptable en las transacciones cotidianas en la provincia. En el único caso en el que en los inventarios aparece este tipo de activo moneda se mencionan "cuatrocientos pesos en billetes del Crédito Público de Buenos Aires de cuya cantidad se hará distribución cuando se halle por conveniente su venta según lo que produjere». AHT, SJ, 62-22.

${ }^{41}$ Irigoin (2006) analiza la evolución de las políticas monetarias en los países hispanoamericanos luego de la independencia y las consecuencias fiscales y comerciales de la coexistencia de diferentes monedas de diferentes calidades en esos espacios.

42 Cfr. Meltzer (1963); Mulligan y Sala-i-Martin (1992); Lewis y Mizen (2000).

43 La primera estimación de una demanda de dinero para una economía pre-industrial es reciente (Nicolini y Ramos, 2006). 
tipo de análisis, como serían la tasa de interés que enfrentan los individuos en el mercado de capitales. Tampoco es posible agregar si estos individuos viven en las ciudades o en el campo o el sector económico al que pertenecen, aunque este enfoque puede intentarse en un desarrollo futuro de la investigación ${ }^{44}$.

Es necesario tener en cuenta en este punto las posibles consecuencias de la coexistencia de moneda buena y moneda mala sobre nuestra aproximación. Como mencionamos en la sección anterior, varias fuentes sugieren que en Tucumán en este período coexisten varias monedas, mientras que en los inventarios la gran mayoría de moneda que aparece está mencionada como plata corriente y parece tratarse de la moneda de plata proveniente de Bolivia (fuerte o feble). Una posible explicación para la escasa presencia de moneda "mala» en nuestra muestra, cuando otras fuentes hablan de escasez de la buena moneda, es que estemos ante el funcionamiento de la Ley de Gresham: la moneda mala es puesta en circulación rápidamente mientras que la moneda mala es reservada para transacciones especiales o para el atesoramiento. Si éste fuera el caso los inventarios recogerían sobre todo la moneda guardada para el atesoramiento y las transacciones diarias se realizarían con moneda mala, generando mayor visibilidad y por lo tanto mayor repercusión en los documentos administrativos que enfatizan el "problema» de la moneda federal y la moneda falsa. Esta situación podría derivar en una especie de segmentación de la demanda de dinero en dos, una para cada calidad de moneda, dependiendo de los retornos de cada una y de las transacciones que se operan con ellas ${ }^{45}$. Si éste fuera el caso, nuestra estimación de la demanda de dinero sería más bien una estimación de la demanda de dinero "bueno» que es el que aparecería registrado en los inventarios más intensivamente ${ }^{46}$.

Para calcular la elasticidad de la demanda de dinero en relación a la riqueza usamos ambas variables en logaritmos, lo cual reduce la muestra a las 47 observaciones que declaran efectivo entre los bienes inventariados. El gráfico 3 muestra los logaritmos de la cantidad de efectivo (logdi) y de la riqueza (logri), donde la asociación positiva se observa claramente.

El resultado de la regresión indica que la elasticidad ingreso del dinero es ligeramente menor a uno y que no podemos descartar la hipótesis de elasticidad unitaria: en este caso el valor de beta es $0,88^{47}$.

\footnotetext{
44 Cfr. Nicolini y Ramos (2006).

45 Sargent y Velde (1999) analizan un problema teóricamente similar pero que emerge por razones diferentes: en este caso la demanda de dinero se separa en dos por la existencia de transacciones que sólo pueden hacerse con monedas de pequeña denominación.

${ }^{46}$ La estimación de demandas diferenciadas según el tipo de moneda es imposible con la aproximación empírica propuesta en este trabajo, dado que de las monedas «malas» son mencionadas sólo en algunos casos.

47 El intervalo de confianza es $(0,59-1,18)$. Ver los resultados completos de la regresión en el apéndice, Regresión 1.
} 
GRÁFICO 3

LOGARITMOS DE LA CANTIDAD DE EFECTIVO Y RIQUEZA EN NIVELES (47 OBSERVACIONES)

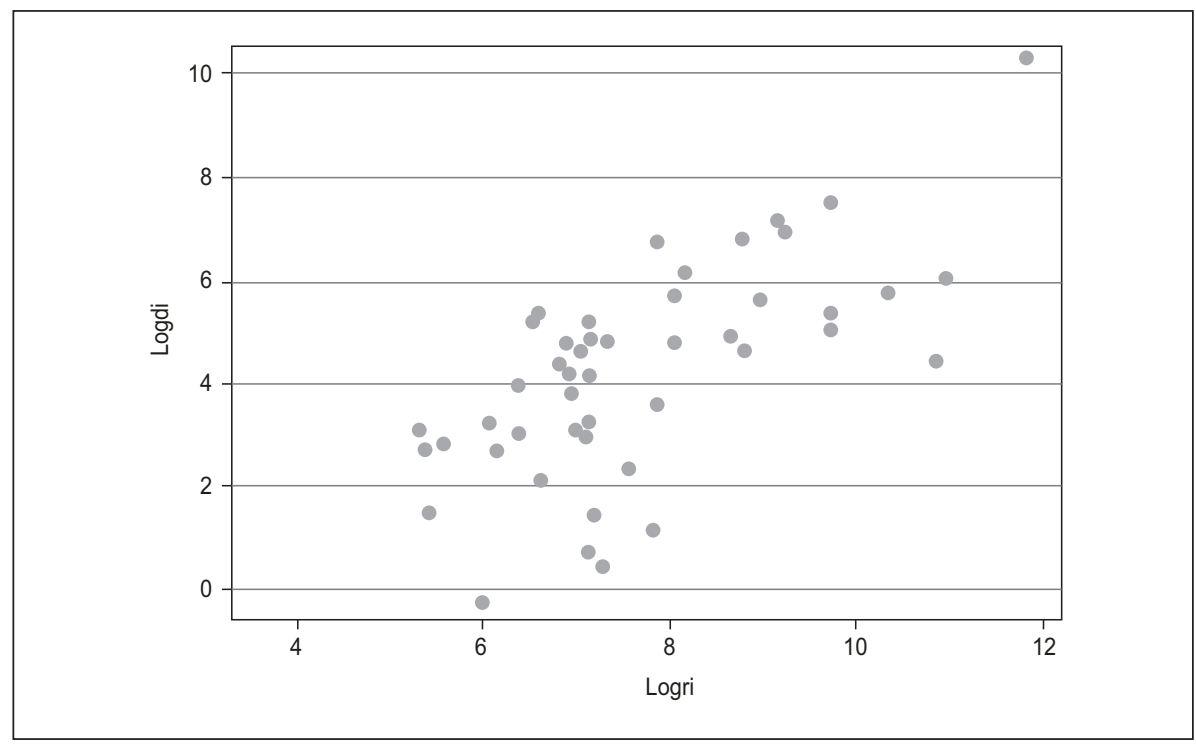

Fuente: Ver texto.

Observando en el gráfico 4 la cantidad de dinero y la riqueza de los 133 inventarios analizados, puede advertirse que existe un inventario que tiene una cantidad de dinero y una riqueza completamente inusuales en nuestra muestra ${ }^{48}$. Al mismo tiempo puede intuirse que aún teniendo altos niveles tanto de riqueza como de dinero, tiene proporcionalmente más dinero que riqueza. Efectivamente, la exclusión de esa variable reduce un poco la elasticidad: el nuevo valor es 0,77 , pero no excluimos la elasticidad unitaria con un nivel de confianza del 95 por cien ${ }^{49}, 50$.

48 Se trata del inventario de José Manuel Silva (AHT, SJ, 88), uno de los más importantes comerciantes de la ciudad. Silva fue administrador de correos según el censo de 1812 (AHT, Sección Administrativa, vol. 22, año 1812), propietario de varias tiendas, pulperías y almacenes entre los años 1820 y 1849 (Padrones de Pago de Patentes, AHT, Sección Hacienda, Mayores y Manuales de Contaduría, años 1823-1850) y uno de los principales contribuyentes en los empréstitos forzosos del período: 1806 (\$100); 1807 (\$40); 1808 (\$25); 1831 (\$300) y $1840(\$ 301)($ AHT, Sección Administrativa, vols. 18 (año 1807) a 55 (año 1840).

49 El intervalo de confianza al 95 por cien es en este caso (0,45-1,09). Los resultados completos también están en el apéndice, Regresión 2.

50 Si se separa la muestra en dos períodos 1820-1840 y 1840-1850, con el segundo período más corto por la menor cantidad de observaciones en la primera parte del período, las elasticidades calculadas para cada uno de ellos son bastante similares. 
GRÁFICO 4

CANTIDAD DE EFECTIVO Y RIQUEZA EN NIVELES (133 OBSERVACIONES)

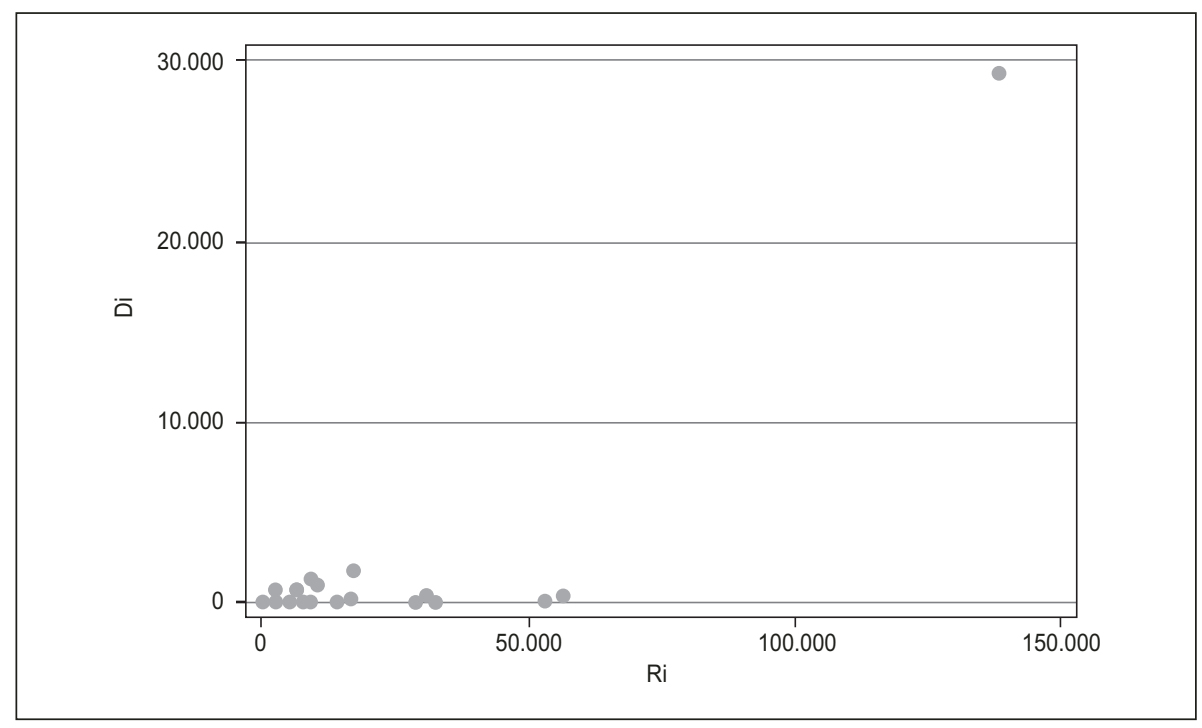

Fuente: Ver texto.

\subsection{Nivel de monetización de la economía}

El porcentaje de riqueza mantenido en forma de efectivo muestra de alguna forma el nivel de monetización de la economía. Según Nicolini y Ramos Palencia (2006) en España en el siglo XVIII este porcentaje alcanzó el 9,4 por cien si se incluyen sólo los inventarios con efectivo y el 4,4 por cien si se incluyen todos.

En la ciudad de San Miguel de Tucumán el dinero existente en los inventarios analizados alcanzó el 9,2 por cien de la riqueza total si incluimos sólo aquellos que reportan efectivo y el 6,4 por cien si incluimos todos los inventarios. En este sentido Tucumán en el siglo xIX parece tener un nivel de monetización similar al de España en el siglo XVIII. La variación temporal muestra un aumento de la monetización en la parte final del período bajo estudio: si consideramos el porcentaje de dinero incluyendo todos los inventarios, el porcentaje de efectivo entre 1820 y 1830 es de sólo 1,6 por cien para aumentar a 3,7 por cien entre 1831 y 1840 y a 9,6 por cien entre 1841 y $1850^{51}$.

51 Este punto parece ser consistente con el aumento del porcentaje de inventarios con efectivo que se produce en la segunda mitad de la muestra. 


\subsection{El valor de la plata sin amonedar}

En los inventarios se menciona muy frecuentemente, incluso en aquellos que indican una riqueza total muy modesta, la existencia de plata labrada o de utensilios de uso diario hechos con plata (fuentes, cucharas, espuelas, mates).

Un elemento interesante de estas menciones es que en la mayoría de los casos se valúa estos bienes por su peso en plata (definido en marcos y onzas) y casi nunca por su valor de uso o artístico ${ }^{52}$. Esto tiene dos implicaciones: por un lado sugiere que frente a la posible escasez de moneda, existía una abundancia relativa de objetos de metal precioso cuyo valor estaba dado sólo por su contenido metálico ${ }^{53}$. Por otro lado, esto nos permite identificar la evolución de la valuación relativa de la moneda en términos de metal precioso. En principio, si la moneda se convirtiera en un bien relativamente escaso esperaríamos que se redujera el valor de la plata labrada y a la inversa en momentos en que la moneda fuera más abundante. También es posible que la calidad de la moneda llamada «corriente» en los inventarios varíe y en ese contexto, una moneda de mayor calidad generaría un precio más bajo de la plata y una moneda con menor valor intrínseco, como la moneda feble boliviana, podría generar un precio mayor de la plata labrada.

La tabla 1 muestra la evolución de la valuación de la plata en términos de moneda corriente

TABLA 1

VALOR DE LA PLATA LABRADA EN PESOS, 1820-1850

\begin{tabular}{|l|c|c|c|c|}
\hline & $\mathbf{1 8 2 0 - 3 0}$ & $\mathbf{1 8 3 1 - 1 8 4 0}$ & $\mathbf{1 8 4 1 - 1 8 4 5}$ & $\mathbf{1 8 4 6 - 1 8 5 0}$ \\
\hline Valor de la plata labrada & 6,43 & 5,90 & 6,00 & 7,62 \\
\hline Observaciones & 7 & 5 & 4 & 12 \\
\hline
\end{tabular}

Fuente. Ver texto.

Dos conjeturas podrían elaborarse a partir de esta información: en primer lugar que la paulatina desaparición de la moneda fuerte del período colonial hizo bajar el precio de la plata labrada hasta la primera década de 1840. Los intentos de acuñar moneda local y la consecuente abundancia de

\footnotetext{
52 En estas valuaciones también se tiene en cuenta la fineza de la plata. Cuando la aleación tiene poco contenido de plata se lo menciona explícitamente y en algunos casos se lo caracteriza como «chafalonía».

53 Segretti (1975) analiza las características de la gestión pública de la política monetaria a nivel provincial. Sargent y Velde (1999) establecen las condiciones teóricas bajo las cuales la conversión de plata en moneda y viceversa son factibles y rentables para los particulares, dadas ciertas estrategias de amonedación por parte del gobierno.
} 
plata falsa en la década de 1820 no habrían afectado la equivalencia entre plata corriente y plata labrada porque la plata federal nunca fue considerada plata corriente para el sector privado, por lo menos tal como lo manifiestan los inventarios. A partir de 1840 la llegada de plata boliviana más abundante por un lado y además de decreciente valor intrínseco generó una caída del valor del numerario y consecuentemente un aumento del valor de la plata amonedada.

\subsection{Valor del oro}

Dado que en varios inventarios hay menciones sobre objetos de oro valuados según su peso, podemos establecer que el valor del oro parece oscilar entre catorce y doce pesos la onza entre 1828 y $1839^{54}$. En 1850 tenemos cuatro menciones del valor del oro: en tres de ellas, que no se explicita si la moneda es plata boliviana, se establecen valores de ocho, seis y cinco reales el adarme respectivamente. Esto supondría dieciséis pesos, doce pesos y diez pesos la onza de oro ${ }^{55}$. Cuando se menciona la relación entre pesos bolivianos y oro, el oro parece claramente más valioso y llega a 18,5 pesos bolivianos la onza ${ }^{56}$. Esto es otra sugerencia de que a finales de la década de 1840, la abundancia relativa de plata y/o la disminución del valor del contenido metálico de la moneda generaron una depreciación de la moneda circulante.

\subsection{La plata federal}

La plata federal aparece mencionada con sus valuaciones en varios inventarios entre 1822 y 1838. La primera mención es del inventario de Salvador de Alberdi, que dice que existen « 925 pesos en dinero federal» pero sin aclarar si hay alguna conversión; es imposible saber si se está tomado el dinero a su valor nominal o si se ha hecho la conversión sin hacerla explícita ${ }^{57}$. En 1825 aparece otra situación similar en el inventario de Paula Suárez, donde los «25 pesos dos reales de plata federal» parecen valuados a su valor nominal pero sin poder excluir la posibilidad de que haya habido una conversión implícita anterior ${ }^{58}$.

El inventario de José Zerdán hace una conversión interesante por explícita: dice que entre los bienes existen «175 pesos en plata federal que hacen

54 En 1828 se tasa a catorce pesos la onza (AHT, SJ, 68, 2), en 1836 a seis reales el adarme o, lo que es lo mismo, a doce pesos la onza (AHT, SJ, 73, 33), en 1839 a doce pesos la onza (AHT, SJ, 76, 17) y en 1840 a catorce pesos la onza (AHT, SJ, 76,8).

55 AHT, SJ, 88, 36 y AHT, SJ, 89, 10.

56 AHT, SJ, 89-8, 1850

57 AHT, SJ, 62-20, 1822.

58 AHT, SJ, 64-6, 1825. 
17 marcos y 5 y $1 / 2$ onzas a 10 reales el marco que totalizan 22 pesos» ${ }^{59}$. O sea que en un período en el cual la valuación de la plata es de poco más de seis pesos el marco, la plata federal aparece valuada aproximadamente en la quinta parte. En 1827 existen dos valuaciones de la chafalonía de plata federal una a cuatro pesos el marco y la otra a dos pesos el marco (inventarios de Pascual Delgado y María Luisa Marturel) ${ }^{60}$. La plata federal valía 2/3 a 1/3 de la plata labrada. El inventario de José Antonio Carmona menciona «593 pesos 3 reales de dinero federal tazamos a razón de catorce pesos corrientes por cada ciento 83 pesos $1 / 2$ real» ${ }^{61}$. O sea que el valor de la plata federal era 1/7 del valor de la corriente en 1828 .

El inventario de Florencio Sal en 1837 menciona «3 marcos en plata federal a veinte reales el marco» ${ }^{62}$. Ya que en ese período el marco de plata labrada era valuado en promedio en 5,9 pesos emerge un ratio de cerca de 2/5 mientras que al año siguiente el inventario de Manuel Monteros tasa los pesos federales a un real por peso o sea $1 / 8^{63}$.

Lamentablemente la cantidad de observaciones es pequeña y la variabilidad de las valuaciones es alta, con lo cual es difícil sacar una conclusión sobre el valor de la moneda federal en relación a la moneda «corriente».

Lo que parece poderse concluir de estos escasos datos es que aún en el período en el cual se supone que la moneda federal «inundaba la plaza», los inventarios no reflejan esta realidad. Tenemos seis inventarios con moneda entre 1820 y 1825 y sólo tres mencionan plata federal; de esos tres, los porcentajes de moneda federal sobre el total es 100 por cien, en uno pero sólo 53 por cien en otro y 29 por cien en el tercero ${ }^{64}$.

\section{CONCLUSIONES}

Este artículo propone un aporte metodológico al sugerir una nueva fuente para entender los fenómenos monetarios en Argentina y probablemente en otros países latinoamericanos durante el siglo XIX. Este período es particularmente complejo desde el punto de vista de la moneda dada la coexistencia de varios tipos de medios de cambio en el mismo espacio y dada la probable utilización discriminada de los diferentes medios en diferentes mercados. En este sentido, los inventarios post-mortem aparecen como una fuente alternativa a las tradicionalmente usadas en estos temas: las fuentes administrativas del sector público y las fuentes contables del sector privado.

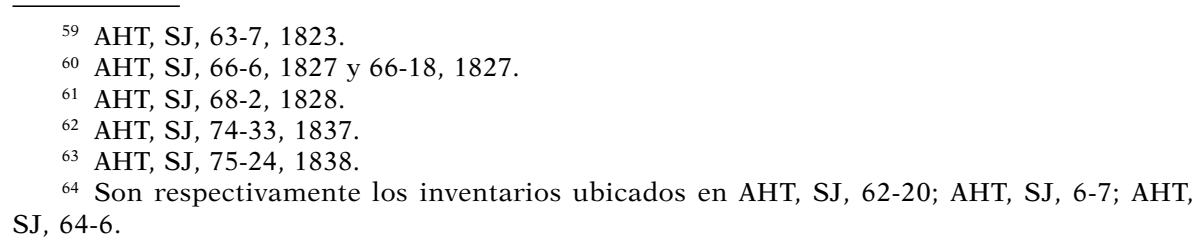


Los resultados obtenidos para Tucumán en relación a los parámetros de la demanda de dinero son estadísticamente significativos, razonables desde el punto de visto teórico y son relativamente semejantes a los obtenidos para economías similares (España en el siglo XVIII) con una metodología equiparable. Esto sugiere que la fuente es robusta y probablemente pueda explotarse más intensamente en el futuro. La elasticidad-riqueza de la moneda es ligeramente inferior a uno, aunque no podemos descartar que sea igual a uno reforzando la idea de una relación proporcional entre la riqueza total y la cantidad de efectivo demandada. Dado el tamaño de la muestra y las limitaciones que surgen de la metodología aplicada a la información disponible, este resultado, al mismo tiempo que debería ser tomado como una hipótesis de trabajo para ser evaluada con más evidencia y bases de datos más amplias, sugiere que la información de los inventarios tiene un gran potencial para ofrecer evidencia empírica nueva sobre el uso de la moneda y su relación con la riqueza de los individuos.

La moneda utilizada en Tucumán como unidad de cuenta es el peso plata. Sólo una mención del papel moneda de Buenos Aires tiende a confirmar que la moneda fiduciaria de Buenos Aires no tenía aceptación en la provincia de Tucumán. No se menciona explícitamente la moneda como «boliviana» o «feble», pero todo apunta a que se trata de esta moneda la que está en circulación. De hecho se observa un aumento significativo de la monetización (porcentaje de moneda sobre riqueza total) coincidente con la expansión de la moneda boliviana en general y feble en particular; la información indirecta del precio de la plata no acuñada y del oro sugiere una mayor oferta de moneda acuñada en la última parte del período estudiado y un descenso del valor de la misma, aunque de magnitud relativamente pequeña. Aunque esto no es una evidencia contundente ni a favor ni en contra de la abundancia de la moneda feble proveniente de Bolivia en el norte argentino, sugiere que es posible que esta moneda circulara pero también sugiere que es probable que este proceso no fuera revolucionario ni haya generado una dinámica de circulación monetaria dramáticamente diferente al período de «escasez» de la década de 1830.

En relación a la moneda federal podemos sugerir, aún reconociendo que la muestra de inventarios es pequeña y que por tanto las conclusiones deben ser tomadas con enorme precaución, que la «mala» moneda no parece ser un gran problema y que seguramente su incidencia parece bastante menor que lo que en otras fuentes y otra bibliografía se sugiere. Esta paradoja puede ser simplemente una confirmación de la ley de Gresham: la mala moneda circula con mucha mayor rapidez que la buena y por tanto aparece mucho más en las transacciones que en la existencia de stocks, más relacionados con la acumulación y la preservación de riqueza.

Dada la intención de realizar un aporte metodológico, la manera natural de ampliar la investigación iniciada en este artículo es expandir la muestra de inventarios analizados tanto extendiendo el período de análisis en la pro- 
vincia de Tucumán como explorando otros puntos de la economía argentina para permitir una valoración de este análisis agregando la perspectiva regional. Otro proceso que puede agregar valor al camino iniciado es la de sistematizar mejor la información disponible sobre los actores económicos involucrados para distinguir comportamientos sistemáticos entre ellos. Por ahora, nuestra sugerencia es que este artículo puede abrir un camino nuevo para entender varias dimensiones de los aspectos monetarios de una región y una época con grandes carencias de información en esta área.

\section{FUENTES}

ARchivo HistóRICO DE TuCUMÁN (AHT):

Sección Administrativa, vols. 18 a 84 (1807-1858).

Sección Judicial Civil, cajas 58 a 89 (1820 a 1850).

Sección Judicial del Crimen, cajas 12, 13, 16, 17 y 19 (1800-1847).

Sección Hacienda. Libros Mayores y Manuales de Contaduría, vols. 1 a 21 (1816-1870).

\section{BIBLIOGRAFÍA}

Allen, R. (1988): «Inferring Yields from Probate Inventories», Journal of Economic History, XLVIII, pp. 117-125.

AMARAL, S. (1988): The rise of capitalism on the Pampas. The Estancias of Buenos Aires, 1785-1870, Cambridge: Cambridge University Press.

Assadourian, C. S. (1981): El sistema de la Economía Colonial. El mercado interior, regiones y espacio económico, México: Nueva Imagen.

Ávila, J. P. (2003): La ciudad arribeña. Tucumán, 1810-1816. Reconstrucción histórica. Tucumán: Ediciones del rectorado-Universidad Nacional de Tucumán.

Bascary, A. M. (1999): Familia y vida cotidiana. Tucumán a fines de la Colonia. Tucumán: Editorial Universidad Pablo de Olavide (Sevilla) y Facultad de Filosofía y Letras (UNT).

Bousquet, A. (1878): El sistema rentístico de la provincia de Tucumán, 1820-1876. Tucumán: Imprenta La Razón.

CAMPI, D. (1996): Aproximación a la génesis de una élite azucarera. Las exportaciones tucumanas en carretas, 1863-1867. Tucumán: Inédito.

Catena, T. (1988): La República de Tucumán y su moneda federal. Buenos Aires: Ediciones Numismática Buenos Aires.

Coastworth, J., y Newland, C. (2000): «Crecimiento económico en el espacio peruano, 1681-1800: una visión a partir de la agricultura», Revista de Historia EconómicaJournal of Iberian and Latin American Economic History, 18, 2, pp. 377-393.

CORTÉs Conde, R. (1989): Dinero, deuda y crisis. Evolución fiscal y monetaria argentina. Buenos Aires: Sudamericana.

Garavaglia, J. C. (1999): Pastores y Labradores de Buenos Aires. Una historia agraria de la campaña bonaerense, 1700-1830. Buenos Aires: La Flor.

Gimenez Zapiola, M. (1975): El régimen oligárquico. Materiales para el Estudio de la Realidad Argentina hasta 1930. Buenos Aires: Amorrortu. 
Goldstone, J. A. (1984): «Urbanization and inflation: Lessons from the English Price Revolution of the Sixteenth and Seventeenth Centuries». American Journal of Sociology, 89, pp. 122-60.

Hora, R. (2006): "El perfil económico de la elite de Buenos Aires en las décadas centrales del siglo XIX». Revista de Historia Económica-Journal of Iberian and Latin American Economic History, 24, 2.

Holderness, B. A. (1976): "Credit in English Rural Society before the Nineteenth Century, with special reference to the period 1650-1720». Agricultural History Review, 24, 2, pp. 97-109.

IRIgoin, M. A. (2003): «La fabricación de moneda en Buenos Aires y Potosí y la transformación de la economía colonial en el Río de la Plata (1820-1860)», en M. A. Irigoin y R. Schmit (eds.): La desintegración de la Economía Colonial. Comercio y moneda en el interior del Espacio Colonial (1800-1860). Buenos Aires: Biblos.

- (2006): «Gresham on horseback: the monetary roots of Spanish American political fragmentation in the nineteenth century», Working Paper 96/06, Department of Economic History, London School of Economics.

JoHnSON, L. (1999): «The frontier as an Arena of Social and Economic Change: Wealth Distribution in Nineteenth-Century Buenos Aires Province», en D. J. Guy y T. E. Sheridan (eds.): Contested Grounds: Comparative Frontiers on the Northern and Southern Edges of the Spanish Empire. Tucson: University of Arizona Press.

LANGER, E. (1987): «Espacios coloniales y economías nacionales: Bolivia y el Norte argentino (1810-1930)». Siglo XIX, 4, pp. 135-160.

LANGER, E., y Conti, V. (1991): "Circuitos Comerciales tradicionales y cambio económico en los Andes Centromeridionales (1830-1930)». Desarrollo Económico, 31, pp. 91-111.

Larrouy, P. A. (1927): Documentos del Archivo de Indias para la Historia de Tucumán, II, siglo XVIII, Tolosa, citado por J. COMADRÁn RuIz (1969): Evolución demográfica argentina durante el período Hispano (1535-1810), Buenos Aires: EUDEBA.

Lewis, M. K., y Mizen, F. (2000): Monetary Economics. Oxford: Oxford University Press.

LINDERT, P. (1985) «English population, wages and prices, 1541-1913». Journal of Interdisciplinary History, XV, pp. 609-634.

Lizondo Borda, M. (1948): Historia de Tucumán. Siglo XIX. Tucumán: Universidad Nacional de Tucumán.

LÓPez de Albornoz, C. (2000): La organización del espacio rural en Tucumán (17701820). Tesis de doctorado, Facultad de Filosofía y Letras, Universidad Nacional de Tucumán.

MaYo, C. A. (1991): «Landed but not Powerful: The Colonial Estancieros of Buenos Aires (1750-1810)». The Hispanic American Historical Review, 71, pp. 761-779.

- (Dir.) (1998): Juego, Sociedad y Estado en Buenos Aires 1730-1830. Buenos Aires: Editorial de la Universidad Nacional de la Plata.

Meltzer, A. H. (1963): «The Demand for Money: The Evidence from the Time Series». Journal of Political Economy, 71, 3, pp. 219-246.

Mitre, A. (1981): Los patriarcas de la plata: estructura socioeconómica de la minería boliviana en el siglo XIX. Lima: IEP.

MULDREW, C. (1998): The economy of obligation: The culture of credit and social relations in Early Modern England. Londres: Macmillan Press.

Mulligan, C., y Sala-I-Martín, X. (1992): «U.S. Money Demand: Surprising Cross Sectional Estimates». Brooking Papers in Economic Activity, 2, pp. 285-329.

Nicolini, E. (1992): "Circuitos comerciales en Tucumán entre 1825 y 1852. Tensión entre el mercado del Pacífico y del Atlántico». Data, 2, pp. 63-96. 
Nicolini, E., y Ramos Palencia, F. (2006): «A methodological approach to estimating the Money demand for pre-industrial economies: probate inventories and the case of Spain in the 18th century». Working Paper, Universidad Carlos III de Madrid.

Nicolini, E., y SCRIMINI, F. (2002): «Hipótesis sobre la situación monetaria de Tucumán 1825-1853», en M. A. IRIGoIn y R. Schmit (eds.): La desintegración de la economía colonial: comercio y moneda en el interior del espacio rioplatense 1800-1860, Buenos Aires: Biblos.

Overton, M. (1979): «Estimating Crop Yields from Probate Inventories: an Example from East Anglia, 1585-1735». Journal of Economic History, XXXIX (1979), pp. 363 378.

Palomeque, S. (1989): «La circulación mercantil en las provincias del interior 18001810». Anuario IEHS, 4, pp. 131-211.

Parolo, M. P. (2006): «La sociabilidad "peligrosa” y las formas de control social en Tucumán en la primera mitad del siglo XIX». Revista Humanitas, núm. 33, Facultad de Filosofía y Letras, Universidad Nacional de Tucumán, año XXV, pp. 309-324.

- (2008): "Ni súplicas, ni ruegos». Las estrategias de subsistencia de los sectores populares en Tucumán en la primera mitad del siglo XIX. Rosario: Prohistoria ediciones (en prensa).

PuccI, R. (1992): «La población y el auge azucarero en Tucumán». Breves Contribuciones del Instituto de Estudios Geográficos, núm. 7, pp. 7-44.

SARgENT, T., y VELDE, F. (1999): «The big problem of small change». Journal of Money Credit and Banking, 31, pp. 137-161.

Scнмiт, R. (2003): «Enlaces conflictivos: comercio, fiscalidad y medios de pago en Entre Ríos durante la primera mitad del siglo XIX», en M. A. Irigoin y R. Schmit (eds.), La desintegración de la economía colonial. Comercio y moneda en el interior del espacio colonial (1800-1860), Buenos Aires: Biblos.

SEgRETTI, C. (1975): Moneda y politica en la primera mitad del siglo XIX (contribución al estudio de la moneda argentina). Tucumán: Fundación Banco Comercial del Norte.

VRIES, J. (1993): «Between purchasing power and the world of goods: understanding the household economy in early modern Europe», en J. Brewer y R. Porter (eds.), Consumption and the World of Goods, London-New York: Routledge, pp. 85-132. 
ESTEBAN A. NICOLINI/MARÍA PAULA PAROLO

\section{APÉNDICE}

\section{RESULTADOS DE LAS REGRESIONES}

REGRESIÓN 1

\begin{tabular}{lccrrrr}
\hline Source & SS & df & MS & & & \\
\hline Model & 85,2271371 & 1 & 85,2271371 & & & \\
Residual & 105,604199 & 45 & 2,34675999 & & & \\
\hline Total & 190,831337 & 46 & 4,14850732 & & & \\
\hline logdi & Coef. & Std. Err. & $\mathbf{t}$ & $\mathbf{P}>\mathbf{| t |}$ & [95\% Conf. Interval] \\
\hline logri & 0,8863926 & 0,1470861 & 6,03 & 0,000 & 0,5901461 & 1,182639 \\
_cons & $-2,621098$ & 1,15264 & $-2,27$ & 0,028 & $-4,942635$ & $-0,2995608$ \\
\hline
\end{tabular}

Number of obs $=47$

$\mathrm{F}(1,45)=36,32$

Prob $>\mathrm{F}=0,0000$

R-squared $=0,4466$

Adj R-squared $=0,4343$

Root MSE $=1,5319$

REGRESIÓN 2

\begin{tabular}{lccrrrr}
\hline Source & SS & df & MS & & \\
\hline Model & 54,4089151 & 1 & 54,4089151 & & & \\
Residual & 98,504882 & 44 & 2,23874732 & & & \\
\hline Total & 152,913797 & 45 & 3,39808438 & & & \\
\hline logdi & Coef. & Std. Err. & $\mathbf{t}$ & $\mathbf{P} \mathbf{| t |}$ & [95\% Conf. Interval] \\
\hline logri & 0,7737924 & 0,1569611 & 4,93 & 0,000 & 0,4574581 & 1,090127 \\
_cons & $-1,818054$ & 1,212762 & $-1,50$ & 0,141 & $-4,262215$ & 0,626106 \\
\hline
\end{tabular}

Number of obs $=46$

$\mathrm{F}(1,44)=24,30$

Prob $>\mathrm{F}=0,0000$

R-squared $=0,3558$

Adj R-squared = 0,3412

Root MSE $=1,4962$ 